\title{
Théâtre de femmes de l'Ancien Régime, Tome II, XVII siècle, A. Evain, P. Gethner et H. Goldwin (éds.)
}

\section{Monica Pavesio}

\section{(2) OpenEdition}

\section{Journals}

\section{Edizione digitale}

URL: http://journals.openedition.org/studifrancesi/9939

DOI: ERREUR PDO dans /localdata/www-bin/Core/Core/Db/Db.class.php L.34 : SQLSTATE[HY000]

[2006] MySQL server has gone away

ISSN: 2421-5856

\section{Editore}

Rosenberg \& Sellier

\section{Edizione cartacea}

Data di pubblicazione: 1 août 2017

Paginazione: 356

ISSN: 0039-2944

\section{Notizia bibliografica digitale}

Monica Pavesio, «Théâtre de femmes de l'Ancien Régime, Tome II, XVIIe siècle, A. Evain, P. Gethner et H. Goldwin (éds.)», Studi Francesi [Online], 182 (LXI | II) | 2017, online dal 01 août 2017, consultato il 07 janvier 2021. URL: http://journals.openedition.org/studifrancesi/9939; DOI: https://doi.org/ERREUR PDO dans /localdata/www-bin/Core/Core/Db/Db.class.php L.34 : SQLSTATE[HY000] [2006] MySQL server has gone away

Questo documento è stato generato automaticamente il 7 janvier 2021.

\section{(c) $(1)$}

Studi Francesi è distribuita con Licenza Creative Commons Attribuzione - Non commerciale - Non opere derivate 4.0 Internazionale. 


\title{
Théâtre de femmes de l'Ancien Régime, Tome II, XVII siècle, A. Evain, P. Gethner et H. Goldwin (éds.)
}

\author{
Monica Pavesio
}

\section{NOTIZIA}

Théâtre des femmes de l'Ancien Régime, Tome II, XVII siècle, édition d'A. EVAIN, P. GETHNER et H. GolDwin, Classiques Garnier, 2015, 604 pp.

1 Dopo qualche rara voce cinquecentesca, la presenza delle donne drammaturgo iniziò a manifestarsi, nel panorama secentesco, solo a partire dalla metà del secolo, quando, nel 1655, la prima donna professionista del teatro francese, Françoise Pascal, pubblicò la sua tragicommedia Agathonphile martyr. Poco tempo dopo, altre tre poetesse e romanziere, Mme de Villedieu, Mme Deshoulières e Anne de La Roche-Guilhen, iniziarono a dedicarsi al teatro. Nonostante gli ostacoli, i pregiudizi e l'ostilità di un'istituzione letteraria chiusa alle donne, questa nuova generazione partì alla conquista del teatro francese secentesco, ottenendo dei risultati tangibili: le loro pièces furono recitate dai migliori attori del tempo nei principali teatri parigini, furono recensite dai giornali e ottennero un buon successo, suscitando l'interesse degli editori.

Il volume Théâtre des femmes de l'Ancien Régime, già pubblicato nel 2008 (Publications de l'Université de Saint-Étienne), viene oggi riproposto nelle Edizioni Classiques Garnier. Un'introduzione generale presenta le cinque autrici che riuscirono, con le loro opere teatrali, a inserirsi nel panorama prevalentemente maschile del teatro francese di metà Seicento, analizza i generi teatrali da loro utilizzati, collega, poi, il lavoro di queste prime donne drammaturgo al rinnovamento del teatro francese e alla corrente del Preziosismo.

3 Sono contenute nel volume le edizioni critiche modernizzate di nove pièces. Quattro furono composte dalla lionese Françoise Pascal: si tratta di due farse, o pièces comiques, 
del 1657, che hanno il pregio di aver rinnovato e migliorato il genere della commedia comica in un atto; di una tragicommedia ispirata dal Grand Cyrus di Madeleine de Scudéry; di una pièce comique del 1664, che riproduce un episodio dell'Astrée. Seguono, poi, una tragedia sacra, dedicata a Santa Caterina d'Alessandria, pubblicata a Parigi nel 1663 dalla Sour de la Chappelle, una religiosa rimasta a tutt'oggi sconosciuta; due tragicommedie, Manlius del 1662 e Le Favori del 1665, scritte da Mme de Villedieu; la comédie-ballet Rare-en-tout, unica pièce di teatro della romanziera protestante Anne de La Roche Guilhen; la tragedia Genséric della poetessa Mme Deshoulières.

4 Concludono il volume un glossario e una succinta bibliografia, che evidenzia lo scarso interesse che fino ad oggi hanno suscitato le cinque autrici e le loro opere. 